\title{
Tensile Properties of Treated and Untreated Ground Nut Shell- Filled Natural Rubber Composites
}

\author{
S. M. Gumel ${ }^{1}$, J. L. Adam ${ }^{1}$, S. Habibu ${ }^{3 *}$, Y. B. Taura ${ }^{2}$ and M. Ladan ${ }^{1}$ \\ ${ }^{1}$ Department of Pure and Industrial Chemistry, Bayero University, P.M.B 3011 Kano, Nigeria \\ ${ }^{2}$ Department of Fashion Design and Clothing Technology, Hussain Adamu Federal Polytechnic, Kazaure, \\ Jigawa State, Nigeria \\ ${ }^{3}$ Department of Chemistry, Federal University Dutse, P.M.B. 7156 Jigawa State, Nigeria
}

*Corresponding Author: habibkuty@gmail.com

\begin{abstract}
Groundnut shell was crushed in to particle size and given two surface treatments with alkali and 3chloro-2-hydroxylpropyltrimethylammoniumchloride respectively. The raw, alkali-treated and bonding agent treated groundnut shell cellulose fibers were used as natural rubber composites. The samples were used to produce fiber-reinforced natural rubber composite at varying filler loadings. Properties such as tensile, hardness and impact of the composites were investigated. The tensile strength of the composites varied such that both the alkali-treated and cationized fillers recorded higher values than untreated fillers. The impact hardness properties were also found to be better in the modified fillers than the untreated ones. This work has shown some general improvements arising from cauticization and cationization of cellulosic filler as reinforcing material for natural rubber.
\end{abstract}

Key words: Cationization, Custicization, Ground nut shell, Natural rubber, Tensile properties

\section{Introduction}

Natural rubber also has been called 'the supreme agricultural colonist of all times'. It is originally indigenous from the Amazon Valley forest, but has been cultivated principally in Southeast Asia, especially for countries like Malaysia and Indonesia. Where more than fourteen million acres of land have been cleared and planted with rubber trees. A considerable amount of research has been done in the field of fiber reinforced elastomer composites. Researchers have studied the effect of different fibers in natural and synthetic rubber for most of these researches petroleum-based resources have been used however, they are non-biodegradable and their disposal contributes to many environmental problems and this prompt researchers to develop biodegradable materials [1]. The investigation of physic-mechanical properties carried out on natural rubbercoconut fiber composites, showed that coconut fiber is potential reinforcing filler for natural rubber compounds. In addition, palm kernel husk was also found to be potential reinforcing filler for natural rubber compounds [2]. Previous work also indicated that the use of lignocellulosic fibers as fillers can improve the properties of polymers and this research work intends to explore the possibilities of using groundnut shell cellulose fibers as potential reinforcement in natural rubber. The most important parameters that affect the fiber-reinforcement are fiber loading, fiber dispersion, fiber orientation and adhesion between the fiber and the matrix [3].

Natural cellulose fiber has the potential to be an attractive alternative to synthetic fiber and is currently being explored in sectors such as the automobile and building industries. In addition, these fibers offer an excellent for use and are of abundant sources. Natural fibers have advantages over synthetic fibers because of their renewable nature, low cost, biodegradability and ease of chemical modification [4].

\section{Experimental}

The reagents used were prepared using standard analytical methods of preparation. The cationizing agent (3-chloro-2-hydroxylpropyltrimethylammoniumchloride) used was obtained from Sigma Aldrich and used as received.

\subsection{Materials}

Crumb natural rubber which conforms to technically specified rubber (TRS) was obtained from Rubber Research Institute of Nigeria (RRIN), Ayonomo, Benin City Edo State. The groundnut shell was obtained from Madobi, Madobi Local Government Area, Kano State.

\subsection{Sample preparation}

The samples were prepared by grinding using a cleaned and dried grinding machine followed by sieving to the particle size of $1 \mathrm{~mm}$. 


\subsection{Moisture content determination}

$1 \mathrm{~g}$ of each sample was put in a watch glass and kept at room temperature for 48 hours. The watch glass containing the sample was recorded as initial weight $\left(\mathrm{W}_{1}\right)$. They were placed in an ovum and maintained the temperature of $100^{\circ} \mathrm{C}$ and continue to weigh at regular intervals of 30 minutes till a constant weight was recorded. The weight was recorded as the final weight $\left(\mathrm{W}_{2}\right)$. The moisture content was determined using the relation:

$\%$ Moisture $=\frac{\mathrm{W}_{1}-\mathrm{W}_{2}}{\mathrm{~W}_{1}} \times 100$

Where $\mathrm{W}_{1}=$ initial weight, and $\mathrm{W}=$ final weight [5].

\subsection{Causticization (Alkali treatment)}

$500 \mathrm{~g}$ of $1 \mathrm{~mm}$ size sample was cautisized by the use of $20 \%$ (owf) sodiumhydroxide solution for 24hours at room temperature after dilution with 7 liters of distilled water. The wet fibers were squeezed to remove excess water and then washed repeatedly to remove excess $\mathrm{NaOH}$. It was finally dried in an ovum at $80^{\circ} \mathrm{C}$ for 5 hours, and pounded to $120 \mu \mathrm{m}$ particle size [5].

\subsection{Cationization}

$500 \mathrm{~g}$ of the caustisized fiber were cationized by the bonding agent 65\% (3-chloro-2hydroxylpropyltrimethylammoniumchloride) at $10 \%$ owf in the presence of $10.92 \% \mathrm{NaOH}$ after dilution with $7800 \mathrm{ml}$ distilled water. The mixture was kept at room temperature for 24 hours maintaining the $\mathrm{pH}$ of 12 by periodic addition of the $10.92 \% \mathrm{NaOH}$ and agitation. The cationized fiber was washed repeatedly to remove the excess $\mathrm{NaOH}$ and the bonding agent. The wet fibers were put in an ovum at $80^{\circ} \mathrm{C}$ for 5 hours to dry and pounded to $120 \mu \mathrm{m}$ particle size [5].

\subsection{Compounding}

The recipe used in the formulation of the natural rubber composites is given in the table below. Mixing was carried out on a laboratory two-roll-mill in accordance with the method described in the American Society for Testing and Materials (ASTM-D3184-80). Cured samples produced on electrically heated press at $150^{\circ} \mathrm{C}$ for 40 minutes under a pressure of 7 torrs.

Table 1: Typical formulation of rubber compounds

\begin{tabular}{|l|l|}
\hline Ingredients & Quantity (phr) \\
\hline Natural rubber & 100 \\
\hline Filler & $0-50$ \\
\hline Zinc oxide & 5.0 \\
\hline Stearic acid & 1.5 \\
\hline Sulphur & 2.5 \\
\hline MBTS & 0.5 \\
\hline
\end{tabular}

MBTS $=$ Mercaptobenzthiazoledisulfide

\subsection{Determination of Physico-mecanical Properties}

\subsubsection{Determination of Tensile Strength}

Tensile properties of the cured composites were measured with Instron universal tester at cross-head speed of $60 \mathrm{mmmin}^{-1}$ using dumb bell shaped test specimens as contained in ASTM-D412-87

\subsubsection{Impact Test}

The impact test was carried out using Resil compactor, model 16650 type 6957 in accordance with the British standard BSEN 6603-2. The total impact mass used is $1.00 \mathrm{~kg}$.

\subsubsection{Hardness Test}

Hardness of the cured composites was measured in shore A, by Durometer instrument, model 5019. The measurement was in accordance with ASTM-D2240.

\subsection{Fourier Transform Infra red Spectroscopy (FTIR)}

FTIIR spectra of the compounded Groundnut shell-Natural rubber were recorded on 8400s Fourier transform infrared spectrophotometer using $\mathrm{KBr}$ pellet technique in the range $4500-400 \mathrm{~cm}^{-1}$ with a resolution of $2 \mathrm{~cm}{ }^{-1}$. 


\section{Results and Discussion}

The alkali treatment (causticization) removed pectin and other soluble carbohydrates like hemicellulose, leaving behind the alkali resistance cellulose. This exposes the hydroxyl group of the fiber and increase bonding sites in the fiber interface. The mechanism of the cationization is as shown:<smiles>C[N+](C)(C)CC(O)CCl</smiles><smiles>C[N+](C)(C)CC1COO1</smiles><smiles>C[N+](C)(C)CC(O)COCl</smiles>

The moisture content of the dry fiber, and cationized fibers show the values of about $8 \%, 7.2 \%$ and $5.6 \%$ respectively. This gives a good dispersion of the fibers in the natural rubber matrix. Similar report was given by [6].

Broad absorption band of hydroxyl group around $3790-3169 \mathrm{~cm}^{-1}$ is attributed to the $\mathrm{OH}$ stretching vibrations of cellulose, hemicelluloses and water absorbed constituents of the fiber. The $\mathrm{OH}$ stretching decreased with custicization, and cationization. The $\mathrm{C}=\mathrm{O}$ stretching vibration of carbonyl groups in hemicelluloses in the fiber can be seen at peak near $1733 \mathrm{~cm}^{-1}$. Those of the custicized and cationized samples have been shifted to $1603 \mathrm{~cm}^{-1}$ and $1722 \mathrm{~cm}^{-1}$ respectively. The presence of aromatic ring in the sample can be seen at $1600-1400 \mathrm{~cm}^{-1}$. The absorption band near $1400-1300 \mathrm{~cm}^{-1}$ may be attributed to aliphatic $\mathrm{C}-\mathrm{H}$ in the plane deformation vibration of methyl or methylene groups. The C-O stretching vibration of aliphatic primary and secondary alcohols in cellulose can be seen in band region $1300-1000 \mathrm{~cm}-1$ [1].

\subsection{Tensile Strength}

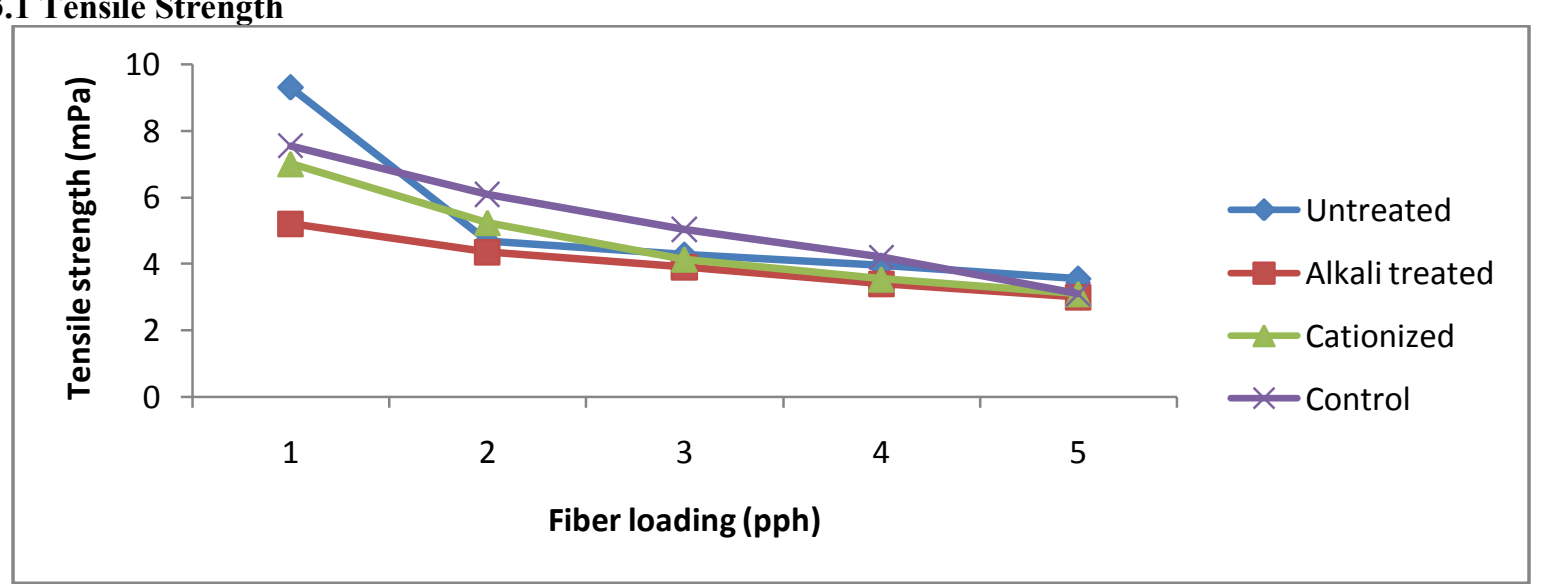

Figure 1: Effect of fiber loading on tensile strength of natural rubber-groundnut shell composites

The tensile strength of the composites shown in fig. 1 and 2 indicated strength decrease with increase in fiber loading. The rubber molecules are themselves internally cross-linked, possessing rather high tensile strength as a result of the so called strain-induced crystallization [5]. However, the addition of the fiber interfered with this natural tendency leading to disruption of the regular arrangement of the molecules, resulting in the loss of ability to crystallize and hence the observed decrease in tensile strength with increase in fiber loading. Figure 1 showed that the tensile strength of the composite filled with causticized and cationized fibers were higher compared to composites made with untreated fibers at most loadings especially of 20 to $40 \mathrm{phr}$. From the result, it is clear that the alkali and bonding agent treated cellulosic fibers gave higher adhesion to rubber matrix [7]. The effect was more pronounced in the cationized fiber composites. 


\subsection{Impact Properties}

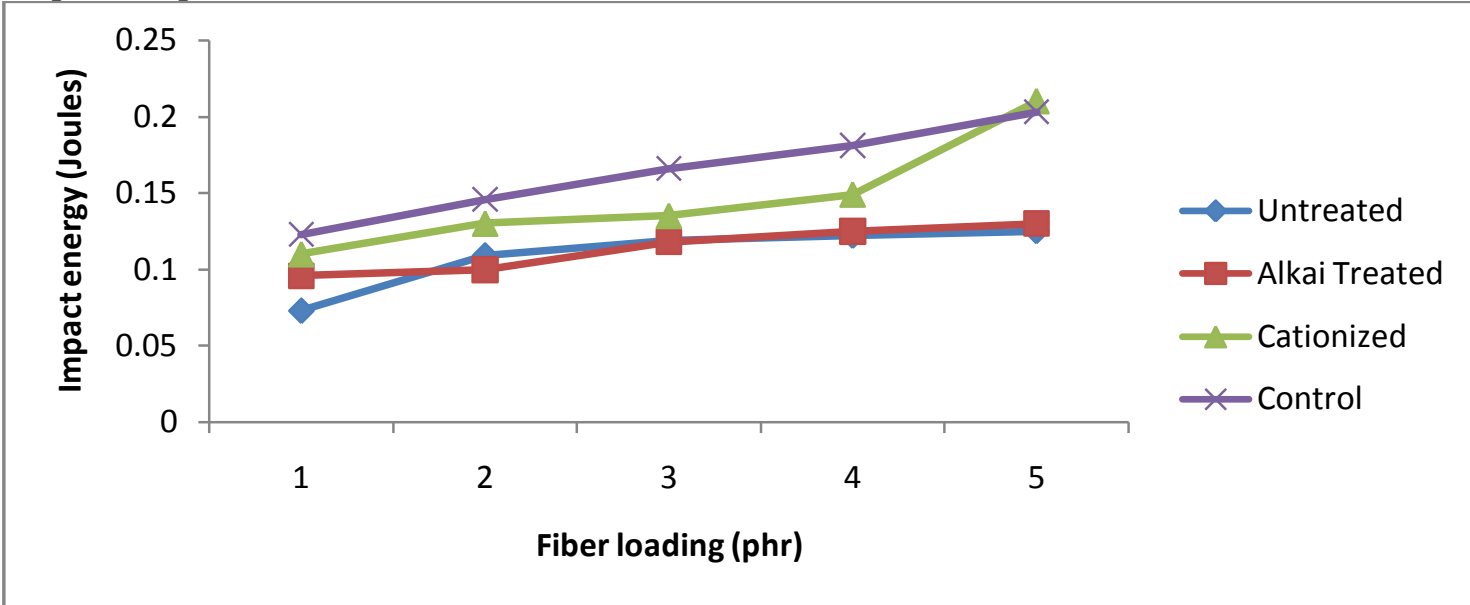

Figure 2: Effect of fiber loading on impact strength of natural rubber-groundnut shell composites

From fig. 2 it can be observed that cationized fibers show better impact properties than the alkalitreated and untreated fibers. The insensitivity of surface treatment with alkali on impact strength was reported by Chuai and his co-workers [8]. Generally, cationized fibers show better impact properties than the alkalitreated and untreated fibers.

\subsection{Hardness Properties}

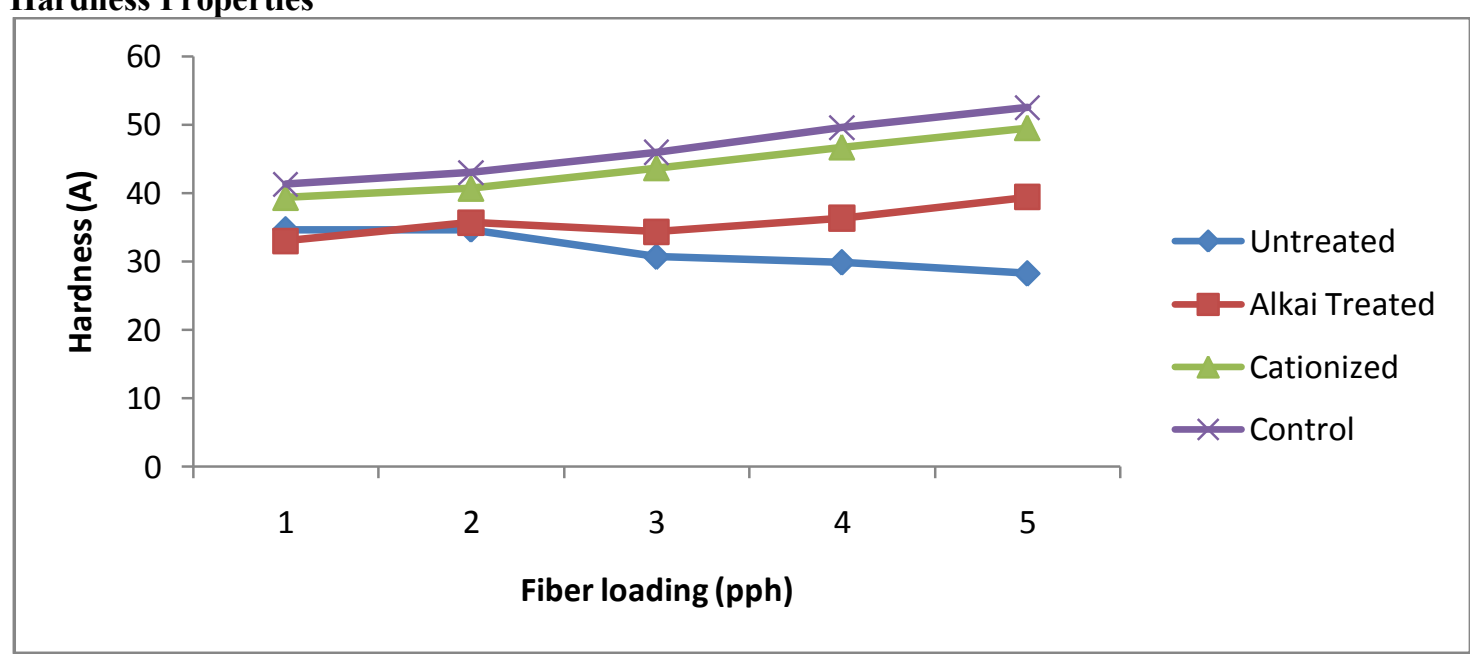

Figure 3: Effect of fiber loading on hardness of natural rubber-groundnut shell composites

The hardness results in fig. 3 of the different samples increased with increasing fiber content. This is in line with the reduced elasticity as a result of the reinforcement in the rubber molecules. Yakubu et. al [5], credited this increase in hardness with fiber loading to the increase in rigidity as the elasticity of the virgin rubber decreases. In the case of untreated groundnut shell fiber, hardness increased with increase in fiber content of the composite of up to $20 \%$ weight fraction. This is because there is decrease in coalescence of the fiber particles which also reduces the rate of getting in of the fiber in to rubber, hence reduced the hardness property $[9,10]$. In each curve, the cationized fiber-reinforced sample gave higher hardness ratings while causticized sample is intermediate between the untreated and cationized samples.

\section{Conclusion}

Two different treatments (custicization and cationization were carried out on ground nut shell cellulosic fiber and the treated as well as the untreated fibers used for the compounding of natural rubber. The Mechanical properties such as impact strength and hardness of both fibers were found to increase with increase in fiber loading. While tensile strength decreases with increase in fiber content of the composites. Therefore the use of wood flour or groundnut shell fibers as filler for natural rubber is of economical value and their consumption as filler would help in reducing environmental waste. 


\section{References}

[1]. M. Z., Abduhamid N. A., Ibrahim and W. Z. Yunus, Effect of grafting on properties of oil palm empty fruit bunch Fiber-Reinforced Biocomposites. Journal of reinforced plastics and composites 29 (18), 2010, 2723-2731

[2]. P. A. Egwaikhide, An investigation on the potential of Palm Kernel Husk as fillers in rubber reinforcement. Middle-east Journal of Science research 2 (1), 2007, 28-32

[3]. V. J. Geethamma and E. Thomas, Standard methods for water and Effluents analysis, (Ibadan Foludex press Ltd. 1996).

[4]. S. Kalia, L. Averurous, J. Njuguna, A. Dufresne, and B. M. Cherian, Natural Fibres Bio-and Nanocomposites. International Journal of Polymer Science doi:10.1155/2011/735932, 2011.

[5]. M. K.. Yakubu, S. M. Gumel and U. Ali, Physico-mechanical effects of surface-modified sorghum stalk powder on reinforced rubber. Journal of reinforced plastics and composites 29 (18), 2010, 2855-2867

[6]. F. E. Okieimen and J. E. Imanah, Characterization of Agricultural waste products as fillers in natural rubber formulation. Nigerian Journal of Polymer Technology 3(1), 2003, 24

[7]. M. Lovely and J. Rani, Mechanical properties of short Ishora-fiber reinforced Natural rubber composites. Journal of applied polymer Science 103, 2006

[8]. S. Chuai Li, S. H., , J. R. De Wijin, De Groot, and B. L. Zhou, Reformed Bamboo / Glass Fabric Aluminium composite as an Ecomaterial. Journal of Materials Science, 33, 1998, 2147-2152

[9]. P. A. Egwaikhide, E. E. Akporhonor and F. E. Okiemen, Effect of coconut fiber filler on the cure characteristic Physico-mechanical and swelling properties of natural rubber vulcanisates. 2007

[10]. A. K. Akinlabi, O. M. Olayinka, E. O. Dare and O. M. Oyenekan, Mechanical Properties of Rubber Blends Filled with Carbonized Pteriocarpus Santalinoides Seed Shell. Nigerian Journal of Polymer Science and Technology 7 (1): 2011, 1-8 